\title{
Correction to: Isolation, Purification, and Culture of Primary Murine Sensory Neurons
}

\author{
Sarah Katzenell, Jorge R. Cabrera, Brian J. North, and David A. Leib
}

Correction to:

Chapter 15 in: Karen Mossman (ed.),

Innate Antiviral Immunity: Methods and Protocols,

Methods in Molecular Biology, vol. 1656,

https://doi.org/10.1007/978-1-4939-7237-1_15

1. In chapter 15 , section 2.3 , the unit " $180 \mu \mathrm{g} / \mathrm{ml}$ mouse laminin in HBSS. Prepare $150 \mu \mathrm{l}$ per coverslip" is corrected to " $18 \mu \mathrm{g} / \mathrm{ml}$ mouse laminin in HBSS. Prepare $150 \mu \mathrm{l}$ per coverslip." 